\title{
An Intelligent Control Strategy for a Highly Reliable Microgrid in Island Mode
}

\author{
Youyun Wang ${ }^{1}$, Yan $\mathrm{Li}^{2, *}{ }^{\mathbb{D}}$, Zhuo Yang ${ }^{2}$ and Xin Cheng ${ }^{2}$ \\ 1 State Key Laboratory of Large Electric Drive System and Equipment Technology, Tianshui Electric Drive \\ Research Institute Co., Ltd., Tianshui 741020, China; wyy@vip.163.com \\ 2 School of Automation, Central South University, Changsha 410083, China; 194612197@csu.edu.cn (Z.Y.); \\ shelleycx@csu.edu.cn (X.C.) \\ * Correspondence: liyanly@csu.edu.cn
}

check for updates

Citation: Wang, Y.; Li, Y.; Yang, Z.; Cheng, X. An Intelligent Control Strategy for a Highly Reliable Microgrid in Island Mode. Appl. Sci. 2022, 12, 801. https://doi.org/ 10.3390/app12020801

Academic Editor:

Amjad Anvari-Moghaddam

Received: 12 November 2021

Accepted: 10 January 2022

Published: 13 January 2022

Publisher's Note: MDPI stays neutral with regard to jurisdictional claims in published maps and institutional affiliations.

Copyright: (c) 2022 by the authors. Licensee MDPI, Basel, Switzerland. This article is an open access article distributed under the terms and conditions of the Creative Commons Attribution (CC BY) license (https:// creativecommons.org/licenses/by/ $4.0 /)$.

\begin{abstract}
An intelligent control strategy based on a membership cloud model in a high reliable offgrid microgrid with a reconfigurable inverter is proposed in this paper. The operating principle of the off-grid microgrid with the reconfigurable inverter is provided, which contains four operating modes. An open-circuit fault diagnosis for the inverter is presented first. The polarities of the midpoint voltages defined in the paper are used to recognize the faulty power switch. The reconfigurable inverter allows the power switches of different bridges to be reconfigured, when there are power switches faulty, to let the inverter operate in faulty state. The working principle of the reconfigurable inverter is given. The membership cloud model with two output channels is built to obtain the virtual impedance to suppress the circulating currents between inverters when the reconfigurable inverter is in faulty state. A pulse resetting method is presented. The general intelligent control strategy for the reconfigurable inverter is formed as the droop-virtual impedance-voltage-current-pulses resetting control. The validity of the intelligent control strategy of the system is verified by simulation.
\end{abstract}

Keywords: reconfigurable inverter; fault diagnosis; membership cloud model; pulses resetting

\section{Introduction}

Power electronic inverters play more and more important roles in many research fields like motor-driven machines, microgrids, photovoltaics (PVs) and so on [1-5]. One of the basic reasons is the increasing incorporation of direct current (DC)-based renewable energy sources (RES) and storage (PVs and batteries) in the grid, for environmental purposes. Another reason is the ascending DC demand in various infrastructures such as data centers, electric vehicle (EV) charging stations, etc. [6-8]. However, the power switches in the inverter are vulnerable to failure for many reasons. Therefore, enhancing the reliability of power electronic inverters becomes more important and has attracted more attention among researchers $[9,10]$.

Real-time fault diagnosis technology is of great significance. In model-based methods, the transient switch voltage signals are analyzed to diagnose the fault quickly [11]. In [12], a new fault feature extraction method based on the trend relationship of adjacent fold lines for data curves is proposed, which can be used to extract the fault features and is not affected by asymmetric interference. When a fault occurs, the currents are distorted. These changes can be used to diagnose the fault [13]. In [14], a current vector instantaneous frequency fault diagnosis method is proposed. It can detect the occurrence of a fault in a very short time, but can't locate the fault. Wavelet packet transforms and Fourier transforms are used to extract the main components of the signals which can effectively reduce the interference of noise and more clearly identify the types of failures $[15,16]$. Reference [17] uses rough set theory to detect short-circuit faults of single-phase inverters. It expresses fault signals in the form of $0-1$, and directly outputs diagnosis results with electronic devices, which simplifies computation. Knowledge-based methods have been the focus 
of recent research. These methods can diagnose the faults accurately. In [16], an on-line estimator constituted by a neural network is used to observe system states, and then fault detection and diagnosis is realized. Reference [18] applies fuzzy control to inverter fault diagnosis, which enhances the anti-interference ability of the system and improves the diagnosis accuracy.

In order to allow circuits to operate smoothly after faults, the fault-tolerance of the inverters needs to be considered. Numerous papers discuss fault tolerant methods for the inverters compromising between costs and reliability. The redundant bridge to keep inverters fault-tolerant operating is usually discussed in many studies [19-22]. These faulttolerant inverter circuits can output good voltages under faulty conditions. However, the general cost is higher because more redundant power switches are needed in fault-tolerant inverters. The three-phase four-switch (TPFS) topology structure is widely applied because of the advantages of the reduced power switches, such as inverters [23,24], active power filters (APF) [25,26], rectifier [27], and so on. Because of the similarity with the three-phase six-switch (TPSS) structure, the TPFS is proposed as a fault tolerant structure for it [28]. In $[29,30]$, a fault tolerant inverter with the TPFS structure in a microgrid is proposed, which keeps the system operating after cutting the fault power switch devices from the inverter. Reference [31] proposes a finite states model predictive direct power control method for TPFS bidirectional alternating current (AC)/DC converters under unbalanced grid voltage conditions, which can realize the fault tolerant continuous operation of bidirectional $\mathrm{AC} / \mathrm{DC}$ converters and eliminate active power or reactive power ripples under unbalanced grid voltage conditions with sinusoidal current waveforms.

An intelligent control strategy based on the membership cloud model is proposed and applied in an off-grid microgrid with a reconfigurable inverter in this paper. There are four novel points. First, one of inverters in the off-grid microgrid system is a reconfigurable one, and can be reconfigured twice when it becomes faulty in power switches. Second, the open circuit fault diagnosis method and the reconfiguring method are presented, which both can be applied twice. Third, the principle of the membership cloud model is presented. The circulating currents between two inverters are suppressed by the virtual impedance based on the membership cloud model. Finally, a corresponding control strategy is proposed, which can work in both normal state and faulty state. In particular, when two inverters are both faulty, one inverter is removed, and the remaining inverter is reconfigured to ensure continuous operation of the off-grid microgrid. The fault-tolerant space has been greatly improved.

The paper is organized as follows: The topology structure and four working modes of the off-grid microgrid with the reconfigurable inverter are presented in Section 2. The open-circuit fault diagnosis method and the reconfiguration method for inverter 1 are presented. The controlling strategy of the off-grid microgrid is presented and discussed in this section. The circulating currents between inverters which are suppressed by the virtual impedance based on the membership cloud model are analyzed when the reconfigurable inverter is faulty. A pulse resetting method which is used in the general control strategy of the system is shown. The simulation results are given in Section 3. The final section presents the conclusions.

\section{Materials and Methods}

\subsection{The Off-Grid Microgrid Topology with a Reconfigurable Inverter}

The topology structure of the off-grid microgrid with a reconfigurable inverter is shown in Figure 1. The off-grid microgrid contains two inverters. Inverter 1 is the reconfigurable one. $\mathrm{V}_{1}-\mathrm{V}_{6}$ are power switches. $\mathrm{TR}_{1} \mathrm{TR}_{2}, \mathrm{TR}_{3}$ and $\mathrm{TR}_{4}$ are four triacs. The inductors $L_{1}, L_{2}$ and capacitor $C$ constitute the LCL filter to compensate the harmonics. Inverter 2 is the normal structure with TPSS. 


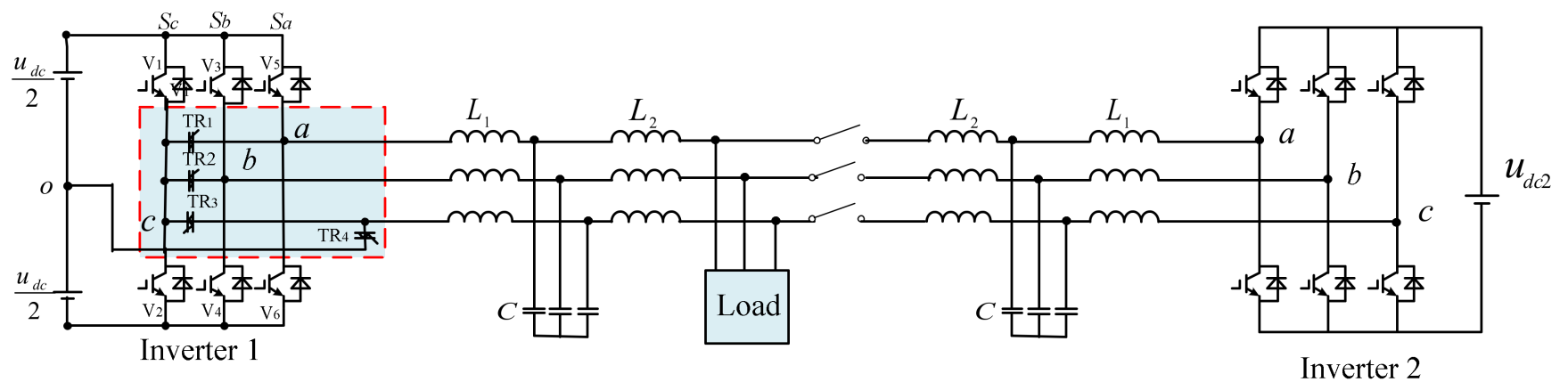

Figure 1. Topology of the off-grid microgrid with the reconfigurable inverter 1.

There are four operating modes in the off-grid microgrid in Figure 1. In the operating mode 1 , both inverters work in their normal state. $\mathrm{TR}_{3}$ is kept on while the other triacs are off in inverter 1 . In the operating mode 2 , inverter 1 works normally, but inverter 2 is detected as faulty by the fault diagnosis method, so it is removed. Both inverters are in faulty operating state in the operating mode 3 . Inverter 1 is reconfigured as a TPFS type while inverter 2 is removed. In the operating mode 4 , inverter 1 is detected to be faulty and is reconfigured as the TPFS type, while inverter 2 works normally. The four operating modes are shown in Table 1.

Table 1. Four operating modes.

\begin{tabular}{ccc}
\hline Modes & Inverter $\mathbf{1}$ & Inverter $\mathbf{2}$ \\
\hline 1 & Normal & Normal \\
2 & Normal & Removed \\
3 & TPFS & Removed \\
4 & TPFS & Normal \\
\hline
\end{tabular}

\subsection{Open-Circuit Fault Diagnosis and Reconfiguration for Inverter 1}

When one of or two of power switches in inverter 1 are faulty, the topology of the inverter 1 will be reconfigured as a three phases four switches (TPFS) structure to keep operating. The corresponding triacs are connected. For example, one of two reconfiguring processes of inverter 1 is shown in Figure 2. Figure $2 \mathrm{a}$ is the equivalent circuit for the reconfigurable inverter 1 . When $V_{1}$ is in open circuit faulty, $T_{4}$ is on and stop trigger $V_{2}$. The DC link takes the place of phase $c$. Then inverter 1 is reconfigured as TPFS as shown in Figure $2 \mathrm{~d}$ and runs continuously. The first reconfiguration is finished, which is shown in Figure $2 b$. If $V_{4}$ is in open circuit faulty for the reconfigured inverter $1, \mathrm{TR}_{4}$ is still on, TR2 on and $V_{2}$ takes the place of $V_{4}$. The second reconfiguration is finished as shown in Figure $2 \mathrm{c}$ and the inverter 1 is reconfigured as TPFS again.

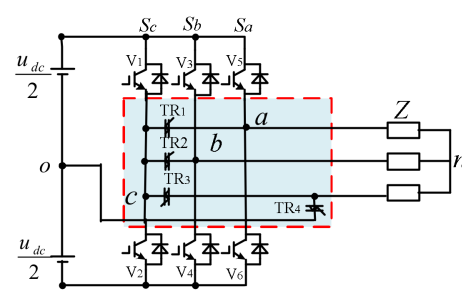

(a)

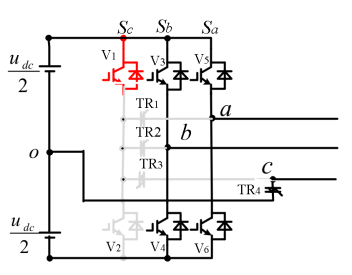

(b)

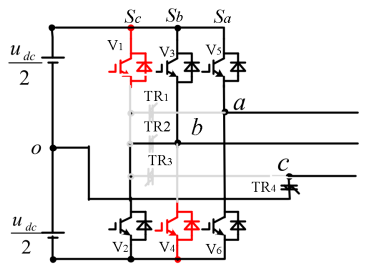

(c)

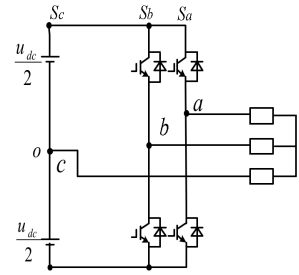

(d)

Figure 2. The one of two reconfiguring processes of inverter 1. (a)The equivalent circuit; (b) The first reconfiguring process; (c) The second reconfiguring process; (d) The reconfigured result as TPFS. 
In Figure $2 \mathrm{a}, u_{a o}, u_{b o}$, and $u_{c o}$ are the midpoint voltages between the midpoint of the three phase bridge arms and the midpoint of the DC side. The fault characteristics of the midpoint voltages are analyzed after an open-circuit fault occurs in the reconfigurable inverter 1 . Then these features are used for fault diagnosis. The fault diagnosis can be used in TPFS and TPSS structures. The bridge switch function $S_{x}$ is set as:

$$
S_{x}=\left\{\begin{array}{l}
1 \text { upper bridge on } \\
-1 \text { lower bridge on }
\end{array},\right.
$$

Here phase $x=(a, b, c)$. The midpoint voltage $u_{x_{0}}$ without fault can be obtained from Figure 2a as:

$$
u_{x o}=\frac{u_{d c}}{2} S_{x}
$$

when $\mathrm{V}_{1}$ is in an open-circuit fault and $S_{c}=1, \mathrm{~V}_{1}$ and $\mathrm{V}_{2}$ are both disconnected, and $c$ is suspended, then $i_{c}=0$. The potential of point $c$ is equal to that of point $n$ and there is $u_{c o F 1}=u_{n o 1}$. The midpoint voltage $u_{c o F 1}$ after the first fault can be obtained:

$$
u_{c o F 1}=u_{n o 1}=\frac{u_{a o 1}+u_{b o 1}}{3}=\frac{u_{d c}}{3}\left(S_{a}+S_{b}\right)-u_{d c}
$$

Then different $S_{a}$ and $S_{b}$ are substituted into the Equation (3), the midpoint voltage of the faulty bridge is obtained as:

$$
u_{c o F 1}<\frac{u_{d c}}{2},
$$

The polarity $J_{x o}$ of the midpoint voltage of the bridge $x$ is defined as:

$$
J_{x o}=J\left[u_{x o F}-u_{x o N}\right] \text {, }
$$

where $u_{x o F}$ denotes the midpoint voltage after one power switch is fault at phase $x$. $u_{x o N}$ is the normal midpoint voltage at phase $x . x=(a, b, c)$. When $\mathrm{V}_{1}$ is in an open-circuit fault and $S_{c}=1$, according to Equations (2) and (4), there is the polarity $J_{c o}$ of the midpoint voltage of the bridge $c$ :

$$
J_{c o 1}=J\left[u_{c o F 1}-u_{c o N 1}\right]=N,
$$

The difference of the midpoint voltage of the bridge before and after fault is less than 0 . That is to say, this polarity of the voltage difference is negative $N$. The reconfiguration process after the fault of inverter $1 . V_{1}$ is removed is shown in Figure $2 b$. TR 4 is triggered on and stops sending triggering pulses to $\mathrm{V}_{2}$. The phase $c$ is replaced by the DC-side capacitors. The inverter can be reconstructed into the TPFS structure which is shown in Figure $2 \mathrm{~d}$. The first fault diagnosis and reconfiguration are finished.

Similarly, the polarity of the midpoint voltage of other bridges can be also obtained when other power switch faults occur. After the faulty power switch is diagnosed, the inverter can be reconfigured to operate in the fault-tolerant state. The results of the first fault diagnosis and reconstruction according to the polarity of the midpoint voltage difference of the bridge are shown in Table 2. The polarities $J_{a o}, J_{b o}$ and $J_{c o}$ of the midpoint voltage of the bridges $a, b$ and $c . Z, N$, and $P$ represent zero, negative, and positive, respectively. "No" means it isn't reconfigured. N-P presents the polarity of the midpoint voltage difference negative when the faulty switch is in the upper bridge and positive when the faulty switch is in the lower bridge.

Take case $1-1$ as example. If $V_{1}$ is detected as faulty, the polarities $J_{a o}$ is negative and $J_{b o}$ and $J_{c o}$ are positive. Then the inverter 1 is reconfigured after the first fault so that the inverter 1 can operate fault-tolerantly. Some power switches can still be used after the reconfiguration in some fault cases. For example, when the faulty $V_{1}$ is removed, $V_{2}$ is still normal. Therefore, $\mathrm{V}_{2}$ can be used for the second reconfiguration when the other power switch in the inverter is detected as faulty. 
Table 2. First fault diagnosis and reconfiguration.

\begin{tabular}{|c|c|c|c|c|c|}
\hline Case & First Fault & $J_{a o}$ & $J_{b o}$ & $J_{c o}$ & On \\
\hline $1-1$ & Normal & $Z$ & $Z$ & Z & $\mathrm{TR}_{3}$ \\
\hline $1-2$ & $\mathrm{~V}_{1}$ & $N$ & $Z$ & $Z$ & $\mathrm{TR}_{4}$ \\
\hline $1-3$ & $\mathrm{~V}_{2}$ & $P$ & Z & $Z$ & $\mathrm{TR}_{4}$ \\
\hline $1-4$ & $\mathrm{~V}_{3}$ & $Z$ & $N$ & Z & $\mathrm{TR}_{2}, \mathrm{TR}_{4}$ \\
\hline $1-5$ & $\mathrm{~V}_{4}$ & $Z$ & $P$ & $Z$ & $\mathrm{TR}_{2}, \mathrm{TR}_{4}$ \\
\hline $1-6$ & $\mathrm{~V}_{5}$ & Z & Z & $N$ & $\mathrm{TR}_{1}, \mathrm{TR}_{4}$ \\
\hline $1-7$ & $\mathrm{~V}_{6}$ & Z & $Z$ & $P$ & $\mathrm{TR}_{1}, \mathrm{TR}_{4}$ \\
\hline $1-8$ & $\mathrm{~V}_{1} \& \mathrm{~V}_{2}$ & $N-P$ & Z & Z & $\mathrm{TR}_{4}$ \\
\hline $1-9$ & $\mathrm{~V}_{1} \& \mathrm{~V}_{3}$ & $N$ & $N$ & Z & No \\
\hline $1-10$ & $\mathrm{~V}_{1} \& \mathrm{~V}_{4}$ & $N$ & $P$ & Z & $\mathrm{TR}_{2}, \mathrm{TR}_{4}$ \\
\hline $1-11$ & $V_{1} \& V_{5}$ & $N$ & Z & $N$ & No \\
\hline $1-12$ & $\mathrm{~V}_{1} \& \mathrm{~V}_{6}$ & $N$ & Z & $P$ & $\mathrm{TR}_{1}, \mathrm{TR}_{4}$ \\
\hline $1-13$ & $V_{2} \& V_{3}$ & $P$ & $N$ & $Z$ & $\mathrm{TR}_{2}, \mathrm{TR}_{4}$ \\
\hline $1-14$ & $\mathrm{~V}_{2} \& \mathrm{~V}_{4}$ & $P$ & $P$ & Z & No \\
\hline $1-15$ & $V_{2} \& V_{5}$ & $P$ & Z & $N$ & $\mathrm{TR}_{1}, \mathrm{TR}_{4}$ \\
\hline $1-16$ & $V_{2} \& V_{6}$ & $P$ & Z & $P$ & No \\
\hline $1-17$ & $V_{3} \& V_{4}$ & Z & $N-P$ & Z & $\mathrm{TR}_{2}, \mathrm{TR}_{4}$ \\
\hline $1-18$ & $V_{3} \& V_{5}$ & Z & $N$ & $N$ & No \\
\hline $1-19$ & $V_{3} \& V_{6}$ & Z & $N$ & $P$ & No \\
\hline $1-20$ & $\mathrm{~V}_{4} \& \mathrm{~V}_{5}$ & Z & $P$ & $N$ & No \\
\hline $1-21$ & $\mathrm{~V}_{4} \& \mathrm{~V}_{6}$ & $Z$ & $P$ & $P$ & No \\
\hline $1-22$ & $\mathrm{~V}_{5} \& \mathrm{~V}_{6}$ & $Z$ & $Z$ & $N-P$ & $\mathrm{TR}_{1}, \mathrm{TR}_{4}$ \\
\hline
\end{tabular}

The primary reconfigured inverter as shown in Figure $2 \mathrm{~d}$ is diagnosed for the second time. Then power switch $V_{4}$ is taken as an example. We can see from Figure $2 d$, when $V_{4}$ has no fault, the voltage of the midpoint of the bridge can be expressed as:

$$
u_{b o N 2}=\left\{\begin{array}{l}
\frac{u_{d c}}{2} S_{b}=1 \\
-\frac{u_{d c}}{2} S_{b}=-1
\end{array},\right.
$$

when $\mathrm{V}_{4}$ has an open-circuit fault and $S_{b}=-1, \mathrm{~V}_{3}$ and $\mathrm{V}_{4}$ are both disconnected, then point $\mathrm{b}$ is suspended and $i_{b}=0$. Potential $b$ is the same as potential $n$. That is $u_{b o F}=u_{n o F}$.

According to Figure $2 \mathrm{~d}$, when $S_{a}=1$ and $S_{b}=-1$, there is the midpoint voltage $u_{b o F}$ after the second fault as:

$$
u_{b \mathrm{oF} 2}=u_{n \mathrm{oF} 2}=\frac{u_{d c}}{2 \times 2 Z} \times Z=\frac{u_{d c}}{4},
$$

when $S_{a}=-1$ and $S_{b}=-1$, there is:

$$
u_{b o F 2}=u_{n o F 2}=-\frac{u_{d c}}{2 \times 2 Z} \times Z=-\frac{u_{d c}}{4},
$$

Finally, considering Equations (7)-(9), there is:

$$
J_{b \circ 2}=J\left[u_{n o F 2}-u_{n o N 2}\right]=P,
$$

That is to say, when an open-circuit fault occurs at $\mathrm{V}_{4}$, the polarity $J_{b o 2}$ of the midpoint voltage difference of the bridge $b$ is positive. The second reconfiguring process is shown in Figure $2 \mathrm{c}$ after the fault of $\mathrm{V}_{4} \cdot \mathrm{V}_{4}$ is removed. $\mathrm{TR}_{4}$ is triggered on and the pulse signal of $\mathrm{V}_{4}$ is sent to $\mathrm{V}_{2}$. The phase $c$ is still replaced by the DC-side capacitors. The inverter can be still reconstructed into the TPFS structure which is shown in Figure 2d. The second fault diagnosis and reconfiguration are finished.

Similarly, the polarity of the midpoint voltage difference of other bridge can be obtained when other power switches fail. The results of the second fault diagnosis and reconfiguration are shown in Table 3. "/" means no need to let any other triacs be on. In Table 3, take case $2-1$ as example. The inverter 1 is already reconfigured as TPFS when 
$V_{1}$ is detected faulty. The polarities $J_{b o}$ is positive. $T_{4}$ and $T R_{2}$ are triggered on and the pulse signal of $\mathrm{V}_{4}$ is sent to $\mathrm{V}_{2}$. The phase $c$ is still replaced by the DC-side capacitors. The inverter 1 can be reconstructed into the TPFS again.

Table 3. Second fault diagnosis and reconfiguration.

\begin{tabular}{ccccccc}
\hline Case & First Fault & Second Fault & $\boldsymbol{J}_{\boldsymbol{a} \boldsymbol{o}}$ & $\boldsymbol{J}_{\boldsymbol{b o}}$ & $\boldsymbol{J}_{\boldsymbol{c o}}$ & On \\
\hline $2-1$ & $\mathrm{~V}_{1}$ & $\mathrm{~V}_{4}$ & $Z$ & $P$ & $\mathrm{Z}$ & $\mathrm{TR}_{2}$ \\
$2-2$ & $\mathrm{~V}_{1}$ & $\mathrm{~V}_{6}$ & $\mathrm{Z}$ & $\mathrm{Z}$ & $P$ & $\mathrm{TR}_{1}$ \\
$2-3$ & $\mathrm{~V}_{2}$ & $\mathrm{~V}_{3}$ & $Z$ & $N$ & $Z$ & $\mathrm{TR}_{2}$ \\
$2-4$ & $\mathrm{~V}_{2}$ & $\mathrm{~V}_{5}$ & $Z$ & $Z$ & $N$ & $\mathrm{TR}_{1}$ \\
$2-5$ & $\mathrm{~V}_{3}$ & $\mathrm{~V}_{2}$ & $N$ & $P$ & $Z$ & $\mathrm{TR}_{2}$ \\
$2-6$ & $\mathrm{~V}_{3}$ & $\mathrm{~V}_{4}$ & $Z$ & $P$ & $Z$ & $/$ \\
$2-7$ & $\mathrm{~V}_{4}$ & $\mathrm{~V}_{1}$ & $P$ & $Z$ & $Z$ & $\mathrm{TR}_{2}$ \\
$2-8$ & $\mathrm{~V}_{4}$ & $\mathrm{~V}_{3}$ & $Z$ & $N$ & $Z$ & $/$ \\
$2-9$ & $\mathrm{~V}_{5}$ & $\mathrm{~V}_{2}$ & $P$ & $Z$ & $Z$ & $\mathrm{TR}_{1}$ \\
$2-10$ & $\mathrm{~V}_{5}$ & $\mathrm{~V}_{6}$ & $Z$ & $Z$ & $P$ & $/$ \\
$2-11$ & $\mathrm{~V}_{6}$ & $\mathrm{~V}_{1}$ & $N$ & $Z$ & $Z$ & $\mathrm{TR}_{1}$ \\
$2-12$ & $\mathrm{~V}_{6}$ & $\mathrm{~V}_{5}$ & $Z$ & $Z$ & $N$ & $/$ \\
\hline
\end{tabular}

The secondary reconfiguration enables the inverter to continue operating in faulttolerant mode and the fault tolerant space is greatly improved to make the system more reliable. We can see from the inference procedure that the second fault diagnosis is the same as the first. The fault diagnosis method can also diagnose dual power switches, which has strong universality. What's more, the reconfigured bridge is always c-phase whichever power switch is faulty, which is convenient to design the control strategy.

\subsection{The Control Strategy for The Off-Grid Microgrid}

\subsubsection{The Circulating Currents Analysis}

In the off-grid microgrid shown in Figure 1, if the parameters between the two inverters are not completely consistent, the amplitude and phase of the output voltages are different, and the line impedances are unequal. The circulating currents between the parallel systems will be generated, resulting in the microgrid produces large losses, which will cause the inverter power switching devices to burn out in serious cases, and affect the stable operation of the entire microgrid. This section analyzes the circulating currents between the two inverters in Figure 1 to design the circulating current suppression strategy to make the microgrid operation safer and more stable. Figure 3 is a schematic diagram of the circulating currents between the inverter 1 and the inverter 2 after reconstruction.

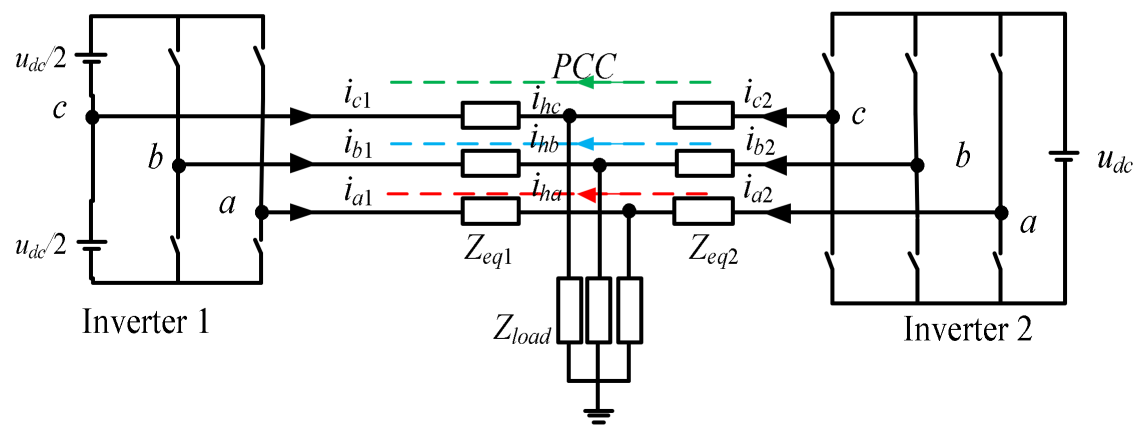

Figure 3. The circulating currents. 
From Figure 3, the output currents of inverter 1 and inverter 2 can be obtained as:

$$
\begin{gathered}
\left\{\begin{array}{l}
i_{a 1}=\frac{u_{d c}\left(2 S_{a}-S_{b}-\frac{1}{2}\right)-3 u_{P C C}}{3 Z_{e q 1}} \\
i_{b 1}=\frac{u_{d c}\left(-S_{a}+2 S_{b}-\frac{1}{2}\right)-3 u_{P C C}}{3 Z_{e q 1}} \\
i_{c 1}=\frac{u_{d c}\left(-S_{a}-S_{b}+1\right)-3 u_{P C C}}{3 Z_{e q 1}}
\end{array}\right. \\
\left\{\begin{array}{l}
i_{a 2}=\frac{u_{d c}\left(2 S_{a}-S_{b}-S_{c}\right)-u_{P C C}}{3 Z_{e q 2}} \\
i_{b 2}=\frac{u_{d c}\left(-S_{a}+2 S_{b}-S_{c}\right)-u_{P C C}}{3 Z_{e q 2}} \\
i_{c 2}=\frac{u_{d c}\left(-S_{a}-S_{b}+2 S_{c}\right)-u_{P C C}}{3 Z_{e q 2}}
\end{array}\right.
\end{gathered}
$$

Among them, $u_{P C C}$ is the voltage at the PCC point. The formula for calculating the circulating current between the two inverters is as follows:

$$
i_{H x}=\frac{i_{x 2}-i_{x 1}}{2}
$$

where, $i_{x 1}$ and $i_{x 2}$ are the output currents of the two inverters respectively, $x=a, b, c$.

Assuming that the equivalent output impedances of the two inverters in the microgrid with reconfigurable inverters are equal, that is $Z_{e q 1}=Z_{e q 2}=Z_{e q}$. The circulating current of each phase between the reconstructed inverter 1 and inverter 2 is:

$$
\left\{\begin{array}{rl}
i_{H a} & =\frac{u_{d c}\left(-4 S_{a}+2 S_{b}+3 S_{c}-\frac{1}{2}\right)}{6 Z_{e q}} \\
i_{H b} & =\frac{u_{d c}\left(2 S_{a}-4 S_{b}+3 S_{c}-\frac{1}{2}\right)}{6 Z_{e q}} \\
i_{H c} & =\frac{u_{d c}\left(2 S_{a}+2 S_{b}-6 S_{c}+1\right)}{6 Z_{e q}}
\end{array},\right.
$$

It can be seen from the above equation that when the equivalent output impedances of the two inverters are the same, the magnitude of the circulating currents generated between the two inverters are affected by the modulation of the switching function. If the equivalent output impedances of the two inverters are inconsistent, the circulating currents will increase further. In order to ensure the safe and stable operation of the microgrid, the circulating currents must be suppressed.

\subsubsection{Adoptable Virtual Impedance Based on the Cloudy Model}

In order to make the equivalent output impedances of the inverter consistent, virtual negative resistance and virtual positive inductances are added to offset the circulation problem caused by unbalanced line impedances and reconstruction and make the equivalent output impedance purely inductive. In this paper, the virtual impedance is designed as:

$$
Z_{v}=-R_{v}+j \omega L_{v}
$$

Among them, $R_{v}$ is the virtual resistance and $L_{v}$ is the virtual inductance. Under the function of $R_{v}$ and $L_{v}$, the equivalent output impedances of the two inverters are adjusted, so that the equivalent output impedance balance is approximately purely inductive.

Since the circulating currents are always changing under the influence of the switching function, and the line impedances are constantly changing under the influence of the environment, the circulating current values are not fixed. If a fixed value of the virtual impedance is used to suppress the changing circulating currents, the suppression effect is poor. The traditional virtual impedance method to suppress circulating current has the characteristics of fixed virtual impedance value and low flexibility. The membership cloud model theory has excellent self-adjustment performance in intelligent control. So an adaptive virtual impedance acquisition algorithm based on the membership cloud model is proposed in this paper, as shown in Figure 4. 


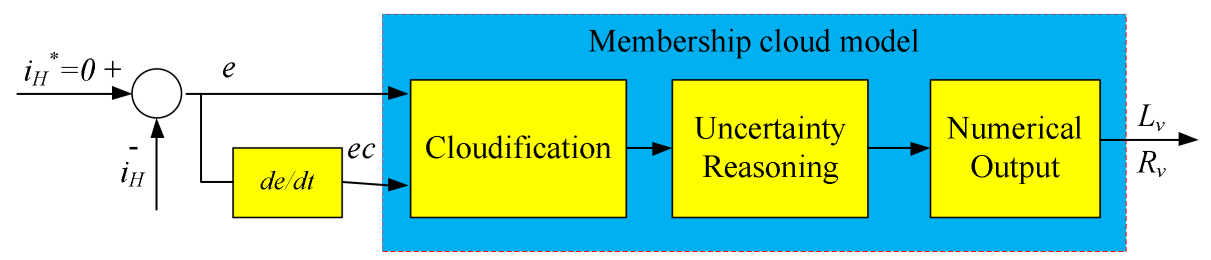

Figure 4. The adaptive virtual impedance from the membership cloud model.

In Figure 4, the numerical input signals are the difference $e$ and the deviation $e c$ of the circulation current. The operating principle structure of the membership cloud model includes mainly three parts: cloudification which is used to cloud numerical input signal values, cloud uncertainty reasoning to get the expected output clouds based on uncertainty reasoning rules and obtaining numerical output signals.

The first step is cloudification that the numerical input signal values are clouded as follows. A random function $R\left(E_{x}, \sigma\right)$ which follows a normal distribution is needed. Parameters $E_{x}$ and $\sigma$ in $R\left(E_{x}, \sigma\right)$ are the expected value and the standard deviation, respectively. If $E_{n}$ and $H_{e}$ are used to denote the expected value and the standard deviation, respectively, a normal random entropy $E_{n}^{\prime}$ with $E_{n}$ and $H_{e}$ is obtained as:

$$
E_{n}^{\prime}=R\left(E_{n}, H_{e}\right)
$$

Then the cloud droplet $x_{i}$ is generated as:

$$
x_{i}=R\left(E_{x}, E_{n}^{\prime}\right) \text {, }
$$

The membership function $\mu_{i}$ can be obtained from Equation (18) which satisfies the normal distribution form:

$$
\mu_{i}=\exp \left\{\frac{-\left(x_{i}-E_{x}\right)^{2}}{2\left(E_{n}^{\prime}\right)^{2}}\right\},
$$

It means that the cloud droplet $x_{i}$ has the degree of membership $\mu_{i}$ in Equation (18). A lot of cloud droplets form a cloud $G\left(E_{x}, E_{n}, H_{e}\right)$.

From Figure 4 it can be seen that there are two input signals $e$ and $e c$, which represent the circulating current difference and the deviation of the circulating current difference, respectively. The clouds of $e$ and $e c$ are expressed as $e\left(E_{x}, E_{n}, H_{e}\right)$ and $e c\left(E_{x}, E_{n}, H_{e}\right)$, which have seven clouds, respectively. Each digital characteristic is calculated by the golden section method [32]. Table 4 shows the digital characteristics for input signals $e$ and $e c$, respectively. The subscripts NB (negative big), NM (negative medium), NS (negative small), Z (zero), PS (positive small), PM (positive medium) and PB (positive big) are fuzzy language sets for the qualitative uncertainty reasoning.

Table 4. Digital characteristics for input signals.

\begin{tabular}{cc}
\hline$e\left(E_{x e}, E_{n e}, H_{e e}\right)$ & $e c\left(E_{x e c}, E_{n e c}, H_{e e} c\right)$ \\
\hline$e_{N B}(-10,3.33,0.42)$ & $e c_{N B}(-3,0.89,0.32)$ \\
$e_{N M}(-3.82,2.06,0.26)$ & $e c_{N M}(-1.21,0.61,0.23)$ \\
$e_{N S}(-1.91,1.27,0.16)$ & $e c_{N S}(-0.58,0.19,0.11)$ \\
$e_{Z}(0,0.79,0.1)$ & $e c_{Z}(0,0.40,0.05)$ \\
$e_{P S}(1.91,1.27,0.16)$ & $e c_{P S}(0.58,0.19,0.11)$ \\
$e_{P M}(3.82,2.06,0.26)$ & $e c_{P M}(1.21,0.61,0.23)$ \\
$e_{P B}(10,3.33,0.42)$ & $e c_{P B}(3,0.89,0.32)$ \\
\hline
\end{tabular}

From Figure 4 it can be seen that there are two output signals $L_{v}$ and $R_{v}$. In the same way, the digital characteristics for output signals $L_{v}$ and $R_{v}$ can be obtained and are shown in Table 5 . 
Table 5. Digital characteristics for output signals.

\begin{tabular}{cc}
\hline $\boldsymbol{L}_{\boldsymbol{V}}\left(\boldsymbol{E}_{\boldsymbol{x} \boldsymbol{L}}, \boldsymbol{E}_{\boldsymbol{n} \boldsymbol{L}}, \boldsymbol{H}_{\boldsymbol{e} \boldsymbol{L}}\right)$ & $\boldsymbol{R}_{V}\left(\boldsymbol{E}_{\boldsymbol{x} \boldsymbol{R}}, \boldsymbol{E}_{\boldsymbol{n} \boldsymbol{R}}, \boldsymbol{H}_{\boldsymbol{e} \boldsymbol{R}}\right)$ \\
\hline$L_{V N B}\left(-6 \times 10^{-4}, 2 \times 10^{-4}, 4.2 \times 10^{-4}\right)$ & $R_{V N B}\left(-2.5 \times 10^{-2}, 8.3 \times 10^{-3}, 8.4 \times 10^{-4}\right)$ \\
$L_{V N M}\left(-2.9 \times 10^{-4}, 1.2 \times 10^{-4}, 2.6 \times 10^{-4}\right)$ & $R_{V N M}\left(-9.5 \times 10^{-3}, 5.2 \times 10^{-3}, 5.2 \times 10^{-4}\right)$ \\
$L_{V N S}\left(-1.9 \times 10^{-4}, 0.76 \times 10^{-4}, 1.6 \times 10^{-4}\right)$ & $R_{V N S}\left(-4.8 \times 10^{-3}, 3.2 \times 10^{-3}, 3.2 \times 10^{-4}\right)$ \\
$L_{V Z}\left(0,0.5 \times 10^{-4}, 1 \times 10^{-4}\right)$ & $R_{V Z}\left(0,2 \times 10^{-3}, 2 \times 10^{-4}\right)$ \\
$L_{V P S}\left(1.9 \times 10^{-4}, 0.76 \times 10^{-4}, 1.6 \times 10^{-4}\right)$ & $R_{V P S}\left(4.8 \times 10^{-3}, 3.2 \times 10^{-3}, 3.2 \times 10^{-4}\right)$ \\
$L_{V P M}\left(2.9 \times 10^{-4}, 1.2 \times 10^{-4}, 2.6 \times 10^{-4}\right)$ & $R_{V P M}\left(9.5 \times 10^{-3}, 5.2 \times 10^{-3}, 5.2 \times 10^{-4}\right)$ \\
$L_{V P B}\left(6 \times 10^{-4}, 2 \times 10^{-4}, 4.2 \times 10^{-4}\right)$ & $R_{V P B}\left(2.5 \times 10^{-2}, 8.3 \times 10^{-3}, 8.4 \times 10^{-4}\right)$ \\
\hline
\end{tabular}

The second step is that the cloud uncertainty reasoning rules are designed. Because there are two input signals $e$ and $e c$, the biconditional rules are needed here, which is shown in Figure 5. For example, If $e=e_{P B}$ and $e c=e c_{P B}$, then $Z_{i}=L_{v P B}$.

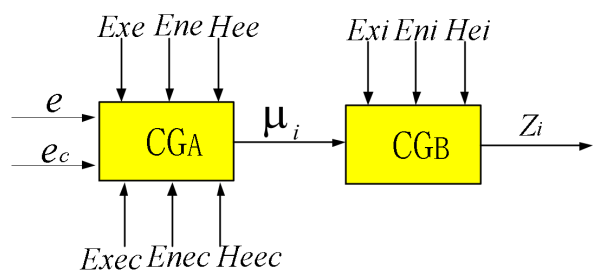

Figure 5. Biconditional rule generator.

In Figure $5, C G_{A}$ is the forward two-dimensional cloud generator. Here cloud generator is represented as CG. It is built from three pairs of digital feature values $\left(\left(E_{x e} E_{x e c}\right),\left(E_{n e}\right.\right.$ $\left.\left.E_{n e c}\right),\left(H_{e e}, H_{e e c}\right)\right)$, and it satisfies:

$$
\mu(e, e c)=\exp \left(\frac{-\left(e-E_{x e}\right)^{2}}{2\left(E_{n e}^{\prime}\right)^{2}}+\frac{-\left(e c-E_{x e c}\right)^{2}}{2\left(E_{n e c}^{\prime}\right)^{2}}\right),
$$

Here $E_{n_{e}}^{\prime}=R\left(E_{n e}, H_{e e}\right)$ and $E_{n_{e c}}^{\prime}=R\left(E_{n e c}, H_{e e c}\right) . C G_{B}$ is the reverse one-dimensional cloud generator with digital characteristic values $\left(E_{x i}, E_{n i}, H_{e i}\right)$, and it satisfies:

$$
Z_{i}=E_{x i} \pm \sqrt{-2 \ln [\mu(e, e c)]} E_{n i}^{\prime}
$$

Here $E_{n e}^{\prime}=R\left(E_{n i}, H_{e i}\right)$. When the deviation $e<E_{x e}$, the \pm in (20) takes a negative signal, otherwise it is a positive sign.$+ Z_{i}$ is the numerical output signal value.

In Figure 6, it can be seen that the membership cloud model has $i(i=1,2, \ldots, n)$ biconditional rules and $n=49$ here. The input signals $e$ and $e c$ stimulate different forward two-dimensional cloud generators $C G_{A i}$ to generate membership $\mu_{A i}$, then $\mu_{A i}$ pass through the reverse one-dimensional cloud generators $C G_{B L i}$ and $C G_{B R i}$ to generate a large number of numeric outputs $Z_{L i}$ and $Z_{R i}$ to get the virtual impedance $L_{v}$ and $R_{v}$, respectively. The final numeric outputs $L_{v}$ and $R_{v}$ are calculated by the weighted average value of $m Z_{L i}$ and $Z_{R i}$, respectively as:

$$
\begin{array}{r}
L_{v}=\frac{\sum_{i=1}^{m} Z_{L i} \mu_{A i}}{\sum_{i=1}^{m} \mu_{A i}}, \\
R_{v}=\frac{\sum_{i=1}^{m} Z_{R i} \mu_{A i}}{\sum_{i=1}^{m} \mu_{A i}},
\end{array}
$$




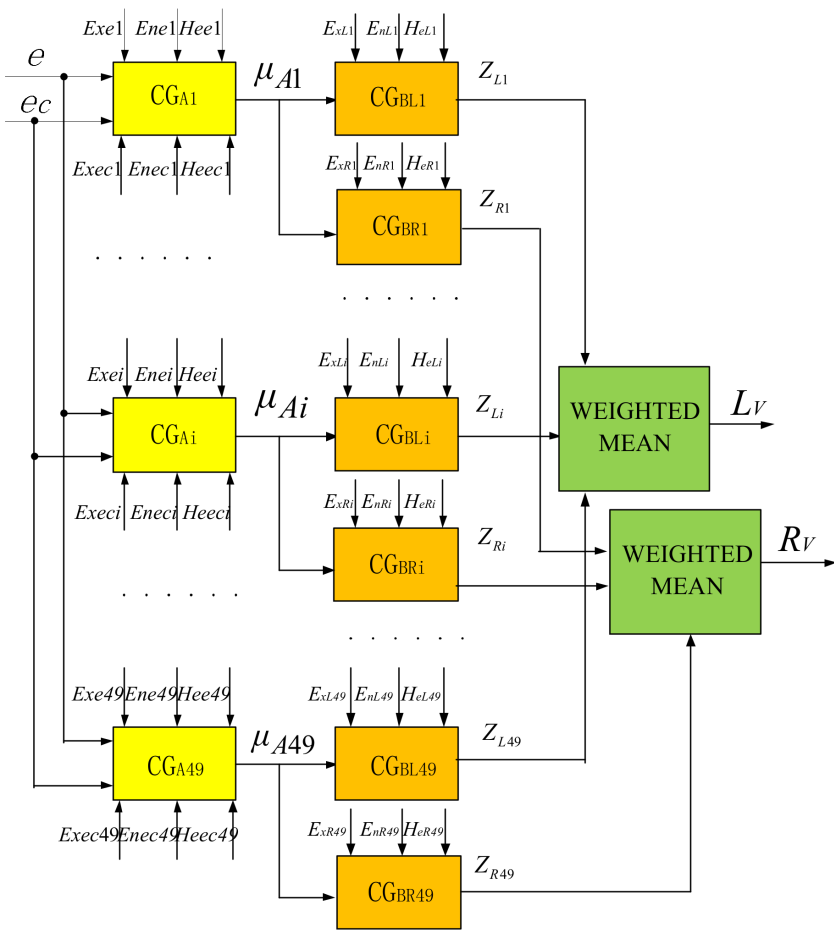

Figure 6. The diagram of rules reasoning for $L_{v}$ and $R_{v}$ with membership cloud model.

\subsubsection{The General Control Strategy}

Figure 7 is the general control strategy of the off-grid microgrid. The control strategy connecting droop-voltage-current three-loop with virtual impedance based on the membership cloud model is applied in inverter 2 , which is shown in the green dashed box.

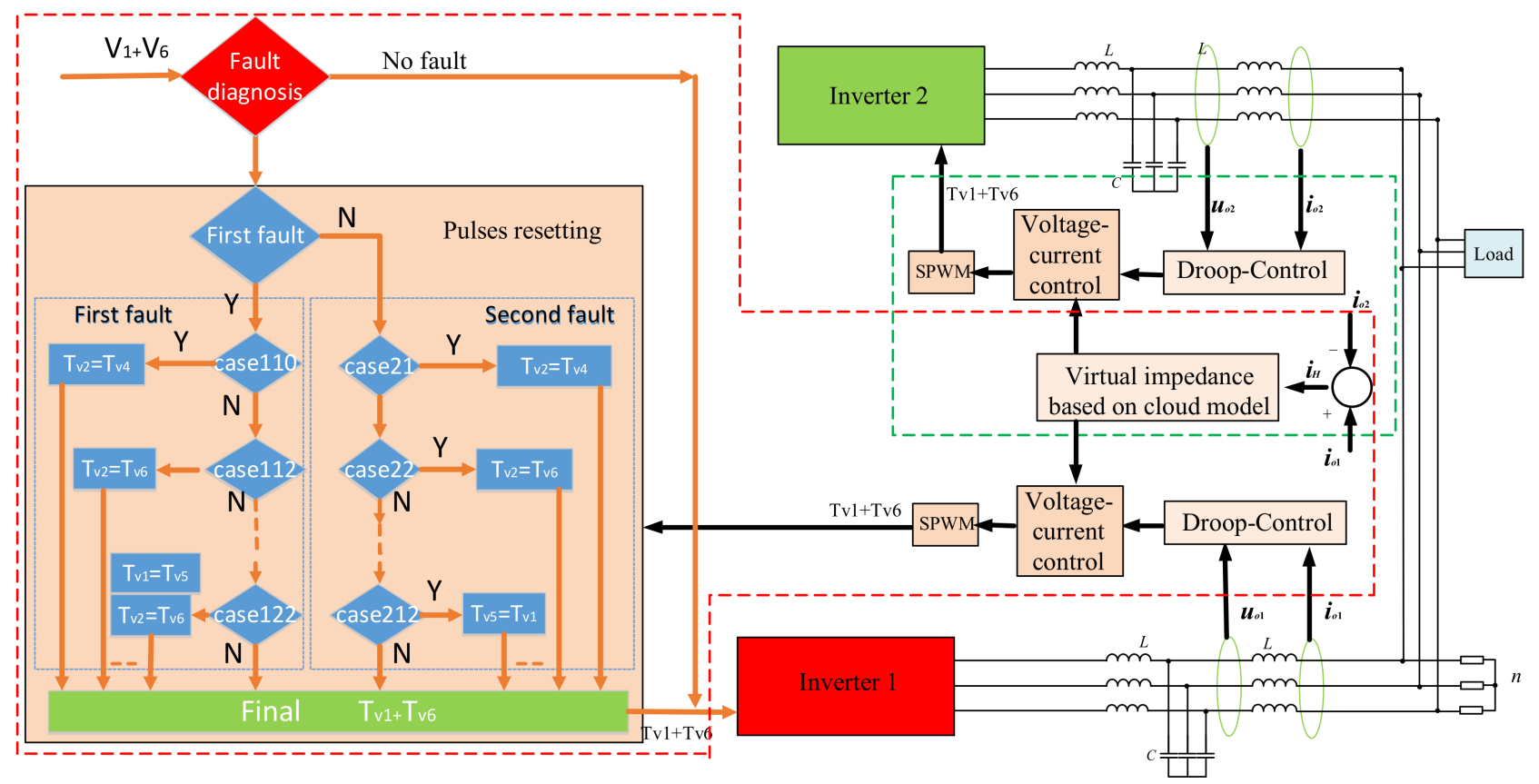

Figure 7. The general control strategy.

The control schematic of the reconfigurable inverter 1 in off-grid microgrid is shown in the red dashed box. When inverter 1 is diagnosed without fault and it runs in normal state, inverter 1 only uses the control strategy connecting droop-voltage-current three-loop 
with virtual impedance based on the membership cloud model, which is also adopted in inverter 2. The virtual impedance voltages in dq coordinates can be obtained as:

$$
\left\{\begin{array}{l}
u_{v d}=i_{o d} \cdot\left(-R_{v}\right)-i_{o q} \omega L_{v} \\
u_{v q}=i_{o q} \cdot\left(-R_{v}\right)+i_{o d} \omega L_{v}
\end{array},\right.
$$

In Equation (23), $i_{o d}, i_{o q}$ are in the $d q$ coordinatea for the output currents $i_{0}$. $\omega$ is the public point voltage frequency. The pulse-resetting is needed when inverter 1 is diagnosed faulty and it runs in faulty state, which is shown in red dashed box. The final pulses $\mathrm{T}_{\mathrm{v} 1}-\mathrm{T}_{\mathrm{v} 6}$ can be obtained for the power switches in inverter 1.

\section{Results and Discussion}

\subsection{Simulating Results and Analysis}

The model of the off-grid microgrid with the proposed twice reconfigurable inverter with twice fault diagnosis based on Figure 1 is built in Matlab Simulink as shown in Figure 8 .

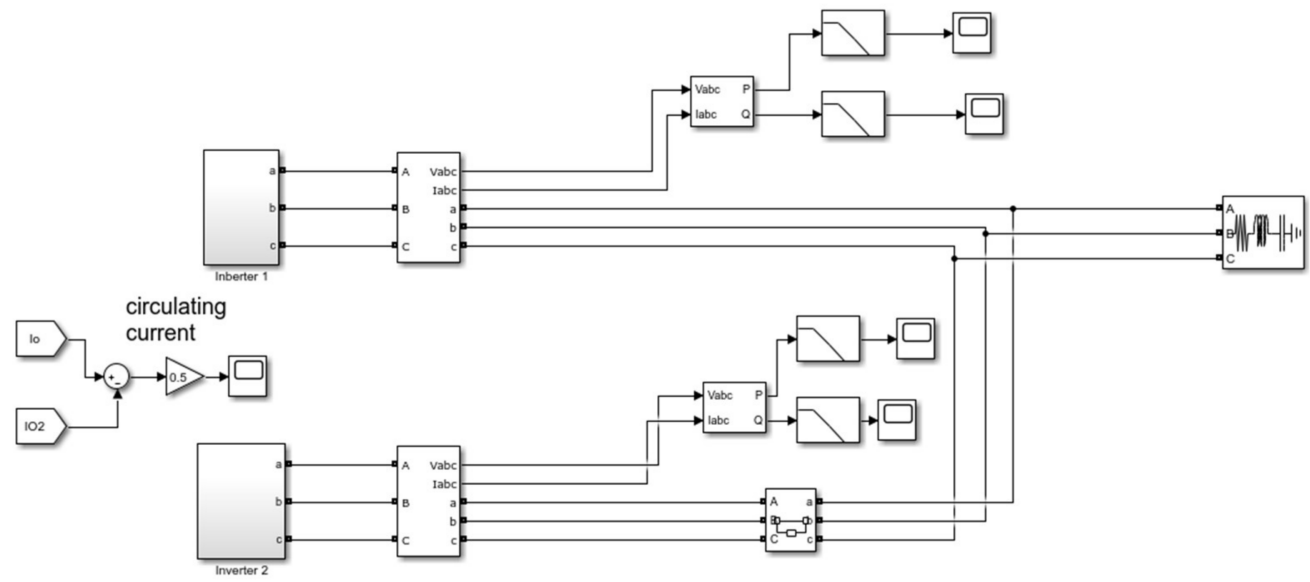

Figure 8. The Matlab Simulink model.

The main simulation parameters are given in Table 6. Two inverters have the same parameters.

Table 6. The main parameters of the simulation model.

\begin{tabular}{cc}
\hline Main Paramenter & Value \\
\hline Given voltage value $U_{m}$ & $380 \mathrm{~V}$ \\
Given voltage frequency $f$ & $50 \mathrm{~Hz}$ \\
The DC side voltage of inverter 1 and 2 & $800 \mathrm{~V}$ \\
The switch frequency of IGBT & $10 \mathrm{k} / \mathrm{Hz}$ \\
The filter inductance $L_{1}$ & $3 \mathrm{mH}$ \\
The filter capacitance $C$ & $5000 \mu \mathrm{F}$ \\
The filter inductance $L 2$ & $3 \mathrm{mH}$ \\
$k_{m}$ and $k_{n}$ of droop control & $1 \times 10^{-5}, 4 \times 10^{-5}$ \\
\hline
\end{tabular}

All four operating modes are simulated. The simulation time is $2 \mathrm{~s}$.

\subsubsection{Operating Mode 1}

In the operating mode 1 , both inverters work normally. The simulation results are given in Figure 9. 


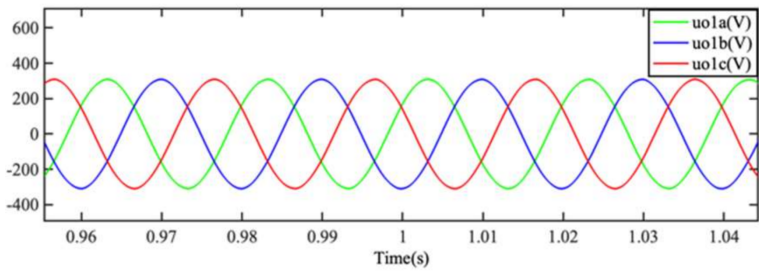

(a)

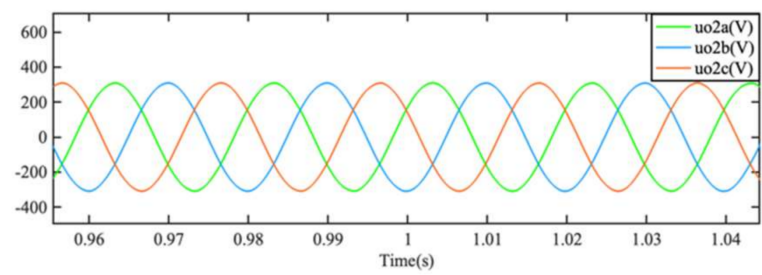

(c)

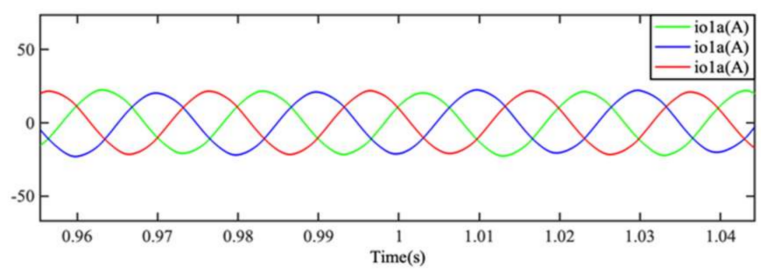

(b)

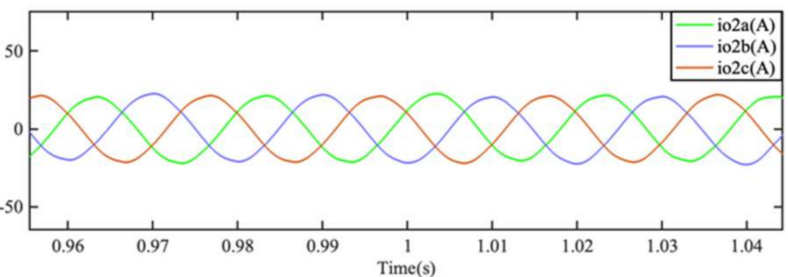

(d)

Figure 9. Simulation results in operating mode 1. (a) The output voltages of inverter $1 ;$ (b) The output currents of inverter $1 ;$ (c) The output voltages of inverter 2; (d) The output currents of inverter 2.

From the operating model simulation results shown in Figure 9 it can be seen that the output voltages and currents of two inverters are equal, with the same amplitude and frequency, which have normal shapes.

\subsubsection{Operating Mode 2}

In operating mode 2, inverter 1 is good while inverter 2 is removed because of breaking down at $\mathrm{t}=1 \mathrm{~s}$. These simulation results are shown in Figure 10 .

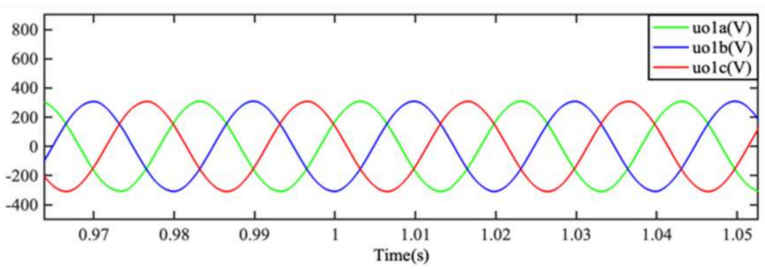

(a)

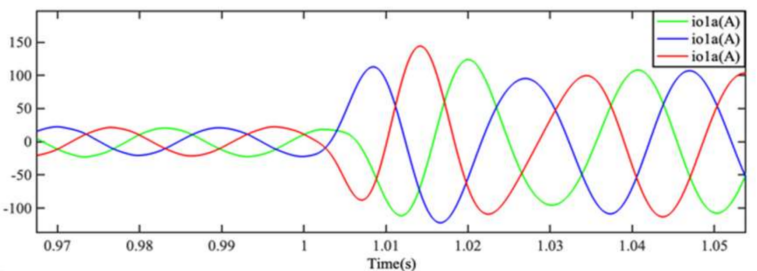

(b)

Figure 10. Simulation results in operating mode 2. (a) Output voltages of inverter 1; (b) Output currents of inverter 1 .

From Figure 10, we can see that the values of output currents in inverter 1 are double the original values at $t=1 \mathrm{~s}$, because inverter 2 is removed. Meanwhile the output voltage waveforms of inverter 1 are kept the same before and after inverter 2 fails, which is same situation as in Figure 9a. The simulation results of the inverter 2 are not given here because it is removed after it failed. The voltages of inverter 1 can be supported by the capacitors in the filter LCL and there is the voltage control in the control strategy, so there are no noticeable changes in the voltages.

\subsubsection{Operating Mode 3}

In operating mode 3 , both inverters are considered to have failed at $t=1 \mathrm{~s}$. At this moment, inverter 2 is removed while inverter 1 is reconfigured. Inverter 1 is faulty again at $1.2 \mathrm{~s}$.

There is a different faulty power switch in inverter 1 at $\mathrm{t}=1 \mathrm{~s}$ and $1.2 \mathrm{~s}$, respectively. The polarities of the inverter 1 midpoint are shown in Figure 11a. The output voltages of inverter 1 are maintained the same good shapes before or after the fault, as are the output currents. However, because inverter 2 is faulty and it is removed at $1 \mathrm{~s}$, the original 
power of inverter 2 is transferred to inverter 1 . Meanwhile the value of output currents in inverter 1 increases. Although inverter 1 has the second fault at $1.2 \mathrm{~s}$, its output voltages and currents can still return good waveforms. From these simulation results, the proposed reconfigured structure and the pulse-resetting for inverter 1 is verified and the microgrid can work continuously under faulty inverter 1 conditions.

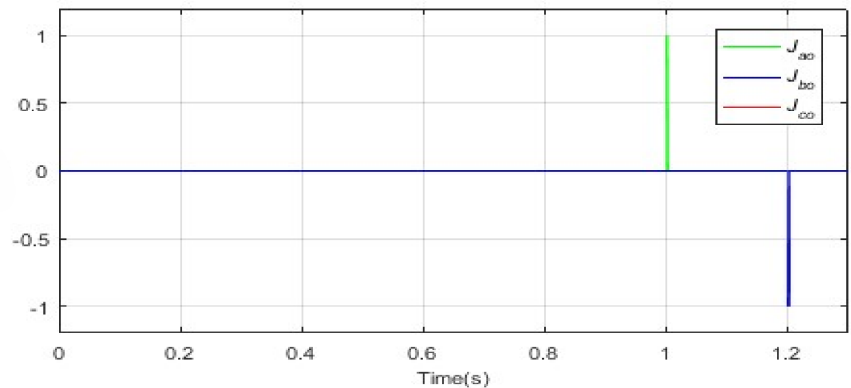

(a)

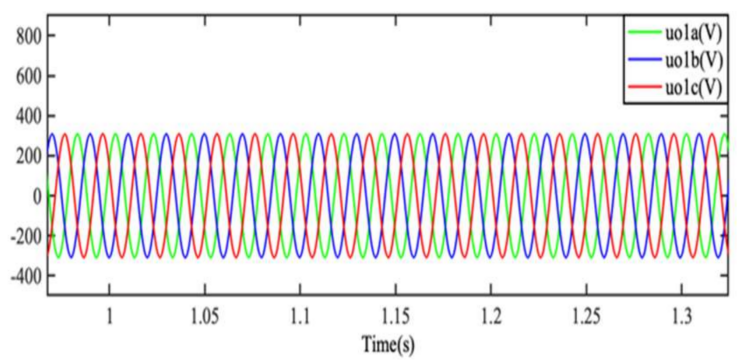

(b)

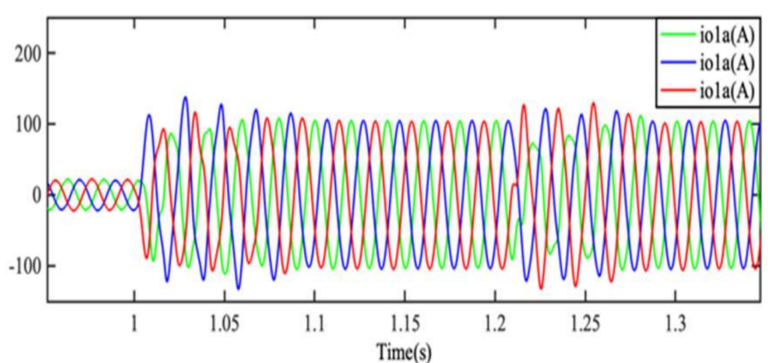

(c)

Figure 11. Operating mode 3. (a) The polarities of the inverter 1 midpoint voltages; (b) Output voltages of inverter 1 ; (c) Output currents of inverter 1.

\subsubsection{Operating Mode 4}

In operating mode 4 , at $\mathrm{t}=1 \mathrm{~s}$ inverter 1 is the first fault and it is the second fault at $\mathrm{t}=1.2 \mathrm{~s}$. Inverter 2 is operating normally all the time. The simulation results in Figure $12 \mathrm{~b}, \mathrm{~d}$ are almost same as those in operating mode 1 . The output voltages and currents of inverter 1 kept good shapes before and after the fault, although inverter 1 is reconfigured twice at $\mathrm{t}=1 \mathrm{~s}$ and $\mathrm{t}=1.2 \mathrm{~s}$, respectively. Because inverter 2 has no fault, these output voltages of inverter 2 are the same in all time. The output currents of two inverters are same whether they work in normal or faulty states, there is hardly any circulation current between the two inverters because of the virtual impedance obtained from the cloud model. The proposed virtual impedance based on the cloud model is verified to suppress the circulation currents between inverters.

\subsubsection{Operating Model without Reconfigured Structure}

Inverter 1 and inverter 2 have completely the same structure and control strategy in this simulating model. There is not reconfigured structure and corresponding pulseresetting in inverter $1 . \mathrm{V}_{1}$ in the inverter 1 is faulty at $\mathrm{t}=0.5 \mathrm{~s}$. Inverter 2 works in the normal state. The simulation results are shown in Figure 13.

According to Figure 13, the output current waveforms of inverter 1 and inverter 2 are distorted and three-phase imbalanced when inverter 1 is faulty. The circulating current is increased greatly. That is to say, the microgrid can't work in its normal state because inverter 1 is faulty. The proposed reconfigured structure and corresponding control strategy can improve greatly the reliability of the microgrid. 


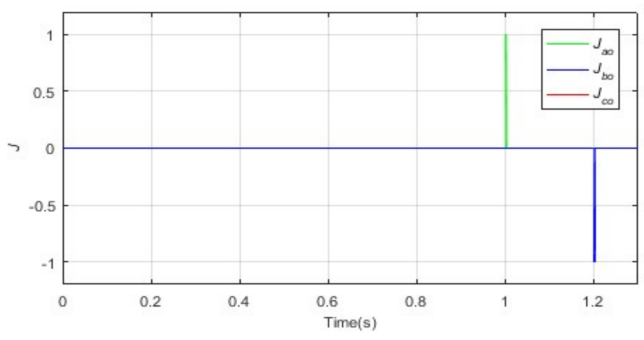

(a)

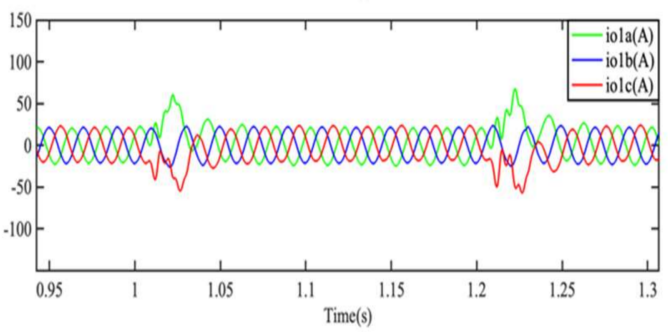

(c)

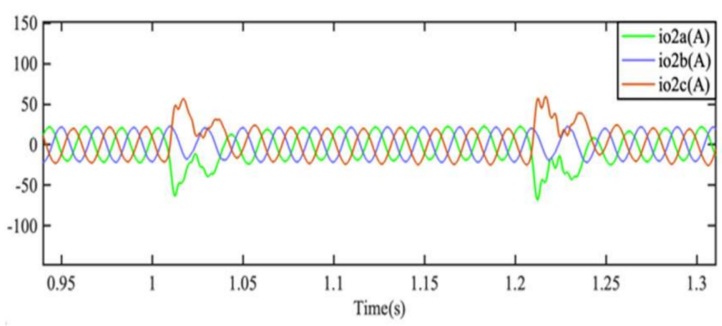

(e)

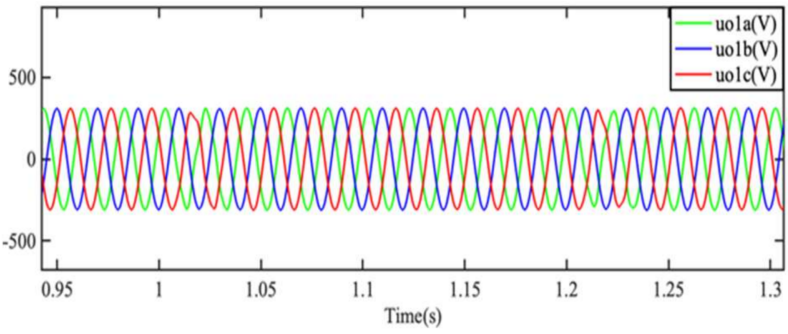

(b)

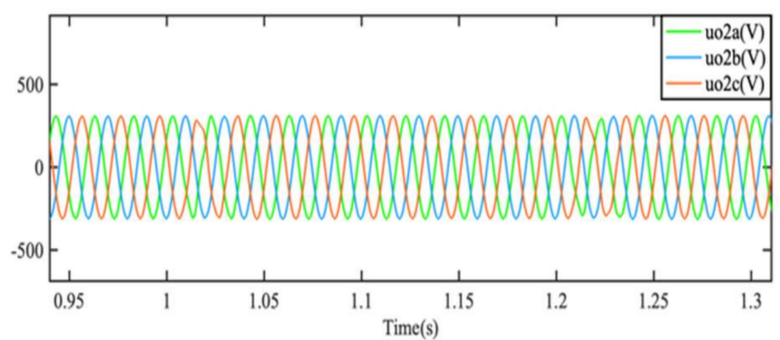

(d)

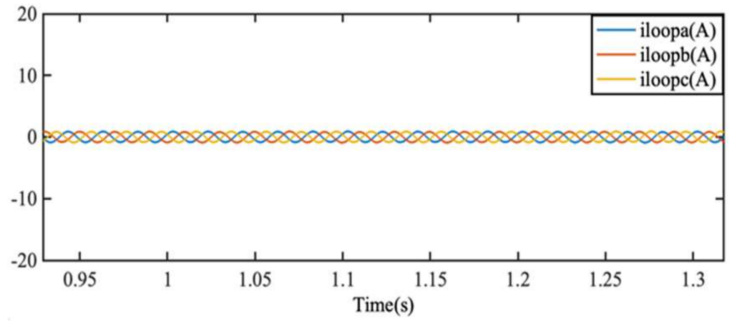

(f)

Figure 12. Operating mode 4. (a) The polarities of the inverter 1 midpoint voltages; (b) The output voltages of inverter 1; (c) The output currents of inverter 1; (d) The output voltages of inverter 2;

(e) The output currents of inverter 2; (f) The circulating currents between inverter 1 and inverter 2 .

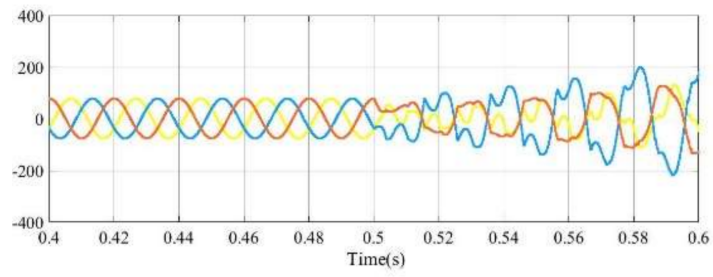

(a)

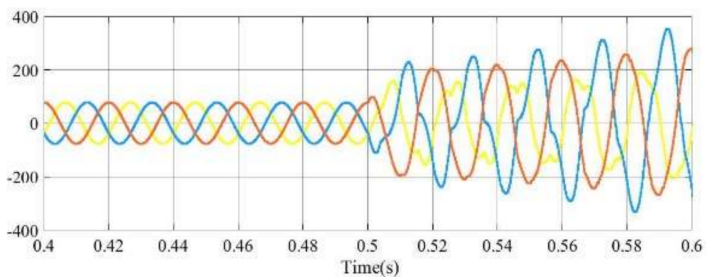

(b)

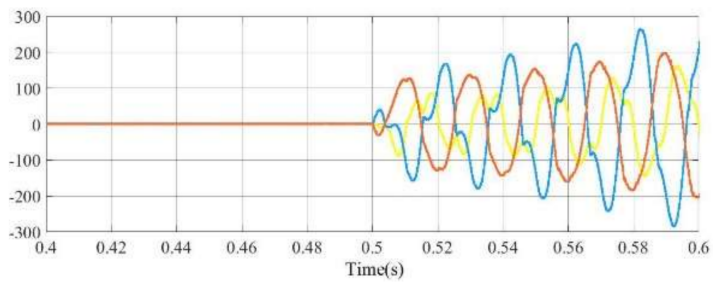

(c)

Figure 13. Simulation results without reconfigured structure and pulse-resetting. (a) The output currents of inverter 1; (b) The output currents of inverter 2; (c) The circulating currents between inverter 1 and inverter 2 .

From all the simulation results, we can see that the output voltages and currents in operating modes 2 and 3 are similar, because inverter 1 is reconfigured to have the 
fault-tolerant function. The output voltages and currents in operating modes 1 and 4 are also similar. It means that if inverter 1 is reconfigured after one or two power switches are in open circuit fault, there is at least one inverter operating continuously in the off-grid microgrid. In operating mode 1 , this is a normal operating mode. Because all parameters of the two inverters are same, there is no circulation current between them. In operating modes 2 and 3, only inverter 1 is working after fault, there is no need to discuss circulation currents. In operating mode 4 , Figure $12 \mathrm{f}$ shows the circulating currents hardly run between the two inverters, whereby the intelligent control strategy is verified. The simulation results without the proposed reconfigured structure and corresponding control strategy are given, which are distorted and imbalanced if inverter 1 is faulty. Compared these results, it is obvious that the reliability of the off-grid microgrid is greatly improved under the proposed reconfigured structure and control strategy.

\section{Conclusions}

An intelligent control strategy for a highly reliable microgrid in off-grid mode with a twice reconfigurable inverter and its fault diagnosis is proposed in this paper. The fault diagnosis method and the reconfiguration can be used twice for inverter 1 . What's more, the reconfigured bridge is always c-phase whichever power switch is faulty, which is good to design the control strategy. The fault-tolerant workspace is large. The circulating currents between the two inverters are analyzed. According to the circulating currents, the virtual impedance based on the membership cloud model is proposed to suppress the circulating currents. A pulse resetting method is adopted, which makes changing the control algorithm before or after the inverter 1 is reconfigured unnecessary, so an intelligent control strategy containing four control loops is formed: the droop control loop, the virtual impedance based on the membership cloud model loop, voltage-current control loop and pulse resetting. Finally, a simulation model is built. The simulation results verify the feasibility of the topology, the fault diagnosis method and the control strategy of the off-grid microgrid with the twice reconfigurable inverter.

Author Contributions: Conceptualization, investigation, formal analysis, writing-review and editing, Y.W. and Y.L.; methodology, software, data curation, writing-original draft preparation, validation and funding acquisition, Y.L.; software, writing-review and editing, Z.Y. and X.C. All authors have read and agreed to the published version of the manuscript.

Funding: This research was funded by Open Fund Project of State Key Laboratory of Large Electric Drive System and Equipment Technology, grant number SKLLDJ012020001.

Institutional Review Board Statement: Not applicable.

Informed Consent Statement: Not applicable.

Conflicts of Interest: The authors declare no conflict of interest.

\section{References}

1. Yu, Z.; Hu, X.; Yao, Z.; Chen, L.; Zhang, M.; Jiang, S. Analysis and Design of a Transformerless Boost Inverter for Stand-Alone Photovoltaic Generation Systems. CPSS Trans. Power Electron. Appl. 2019, 4, 310-319.

2. Firuzi, M.F.; Roosta, A.; Gitizadeh, M. Stability Analysis and Decentralized Control of Inverter-Based AC Microgrid. Prot. Control Mod. Power Syst. 2019, 4, 65-86.

3. Ouanjli, N.E.; Derouich, A.; Ghzizal, A.E.; Taoussi, M.; Bossoufi, B. Direct torque control of doubly fed induction motor using three-level NPC inverter. Prot. Control Mod. Power Syst. 2019, 4, 196-204. [CrossRef]

4. Li, K.; Cheng, S.; Yu, T.; Wu, X.; Xiang, C.; Bilal, A. An On-Line Multiple Open-Circuit Fault Diagnostic Technique for Railway Vehicle Air-Conditioning Inverters. IEEE Trans. Veh. Technol. 2020, 69, 7026-7039. [CrossRef]

5. Daoudi, S.E.; Lazrak, L.; Lafkih, M.A. Sliding mode approach applied to sensorless direct torque control of cage asynchronous motor via multi-level inverter. Prot. Control Mod. Power Syst. 2020, 5, 166-175. [CrossRef]

6. Fotopoulou, M.; Rakopoulos, D.; Trigkas, D.; Stergiopoulos, F.; Blanas, O.; Voutetakis, S. State of the art of low and medium voltage direct current (Dc) microgrids. Energies 2021, 14, 5595. [CrossRef]

7. Nguyen, T.H.; Van, T.L.; Nawaz, A.; Natsheh, A. Feedback Linearization-Based Control Strategy for Interlinking Inverters of Hybrid AC/DC Microgrids with Seamless Operation Mode Transition. Energies 2021, 14, 5613. [CrossRef] 
8. Betta, G.; Capriglione, D.; Ferrigno, L.; Laracca, M.; Miele, G.; Polese, N.; Sangiovanni, S. A Fault Diagnostic Scheme for Predictive Maintenance of AC/DC Converters in MV/LV Substations. Energies 2021, 14, 7668. [CrossRef]

9. Zhang, W.; Xu, D. Fault Analysis and Fault-Tolerant Design for Parallel Redundant Inverter Systems in Case of IGBT Short-Circuit Failures. IEEE J. Emerg. Sel. Top. Power Electron. 2018, 6, 2031-2041. [CrossRef]

10. Yang, S.; Bryant, A.; Mawby, P.; Xiang, D.; Ran, L.; Tavner, P. An industry-based survey of reliability in power electronic converters. IEEE Trans. Ind. Appl. 2011, 47, 1441-1451. [CrossRef]

11. Chen, M.; Xu, D.; Zhang, X.; Zhu, N.; Wu, J.; Rajashekara, K. An Improved IGBT Short-Circuit Protection Method with Self-Adaptive Blanking Circuit Based on VCE Measurement. IEEE Trans. Power Electron. 2018, 33, 6126-6136. [CrossRef]

12. Huang, Z.; Wang, Z. A Fault Diagnosis Algorithm for Microgrid Three-Phase Inverter Based on Trend Relationship of Adjacent Fold Lines. IEEE Trans. Ind. Inform. 2019, 16, 267-276. [CrossRef]

13. Shi, T.; He, Y.; Wang, T.; Tong, J.; Li, B.; Deng, F. An Improved Open Switch Fault Diagnosis Technique of a PWM Voltage Source Rectifier Based on Current Distortion. IEEE Trans. Power Electron. 2019, 34, 12212-12225. [CrossRef]

14. Cecati, C.; Di Tommaso, A.O.; Genduso, F.; Miceli, R.; Galluzzo, G.R. Comprehensive Modeling and Experimental Testing of Fault Detection and Management of a Nonredundant Fault-Tolerant VSI. IEEE Trans. Ind. Electron. 2015, 62, $3945-3954$.

15. Huang, Z.; Wang, Z.; Zhang, H. A Diagnosis Algorithm for Multiple Open-Circuited Faults of Microgrid Inverters Based on Main Fault Component Analysis. IEEE Trans. Energy Convers. 2018, 33, 925-937. [CrossRef]

16. Gan, C.; Wu, J.; Yang, S.; Hu, Y.; Cao, W.; Si, J. Fault diagnosis scheme for open-circuit faults in switched reluctance motor drives using fast Fourier transform algorithm with bus current detection. IET Power Electron. 2016, 9, 20-30. [CrossRef]

17. Oliveira, A.B.D.M.; Moreno, R.L.; Ribeiro, E.R. Short-circuit fault diagnosis based on the rough sets theory for a single-phase inverter. IEEE Trans. Power Electron. 2019, 34, 4747-4764. [CrossRef]

18. Hadjou, F.; Tabbache, B.; Henini, N.; Benbouzid, M. Diagnosis of PWM Power Inverter Based on Fuzzy Logic and Concordia Current Pattern. In Proceedings of the International Conference on Applied Smart Systems, Medea, Algeria, 24-25 November 2018.

19. Mirafzal, B. Survey of fault-tolerance techniques for three-phase voltage source inverters. IEEE Trans. Ind. Electron. 2014, 61, 5192-5202. [CrossRef]

20. Xu, S.; Zhang, J.; Hang, J. Investigation of a Fault-Tolerant Three-Level T-Type Inverter System. IEEE Trans. Ind. Appl. 2019, 53, 4613-4623. [CrossRef]

21. Wang, B.; Li, Z.; Bai, Z.; Krein, P.T.; Ma, H. A Redundant Unit to Form T-type Three-Level Inverters Tolerant of IGBT Open-Circuit Faults in Multiple Legs. IEEE Trans. Power Electron. 2020, 35, 924-939. [CrossRef]

22. Wang, B.; Li, Z.; Dong, M.; Bai, Z.; Krein, P.T.; Ma, H. Recovering Partial Three-level Operation in a T-type Inverter with Fault Management Redundant Unit. IEEE Trans. Power Electron. 2020, 35, 8944-8955. [CrossRef]

23. Zaky, M.S.; Metwaly, M.K. A Performance Investigation of a Four-Switch Three-Phase Inverter-Fed IM Drives at Low Speeds Using Fuzzy Logic and PI Controllers. IEEE Trans. Power Electron. 2017, 32, 3741-3753. [CrossRef]

24. Hoang, K.D.; Zhu, Z.Q.; Foster, M.P. Influence and compensation of inverter voltage drop in direct torque-controlled four-switch three-phase PM brushless AC drives. IEEE Trans. Power Electron. 2011, 26, 2343-2357. [CrossRef]

25. Tan, X.; Li, Q.; Wang, H.; Cao, L.; Han, S. Variable parameter pulse width modulation-based current tracking technology applied to four-switch three-phase shunt active power filter. IET Power Electron. 2013, 6, 543-553. [CrossRef]

26. Luo, Z.; Su, M.; Sun, Y.; Zhang, W.; Lin, Z. Analysis and control of a reduced switch hybrid active power filter. IET Power Electron. 2016, 9, 1416-1425. [CrossRef]

27. Lee, T.S.; Liu, J.H. Modeling and control of a three-phase four-switch PWM voltage-source rectifier in d-q synchronous frame IEEE Trans. Power Electron. 2011, 26, 2476-2489. [CrossRef]

28. Badsi, B.E.; Bouzidi, B.; Masmoudi, A. DTC scheme for a four-switch inverter-fed induction motor emulating the six-switch inverter operation. IEEE Trans. Power Electron. 2013, 28, 3528-3538. [CrossRef]

29. Dasgupta, S.; Mohan, S.N.; Sahoo, S.K.; Panda, S.K. Application of four-switch-based three-phase grid-connected inverter to connect renewable energy source to a generalized unbalanced microgrid system. IEEE Trans. Ind. Electron. 2013, 60, 1204-1215. [CrossRef]

30. Li, Y.; Li, B.; Shuai, Z.; Shen, Z.J. A fault tolerant topology of inverter for micro-grid. Proceedings of the IEEE International Conference on Industrial Technology. Taibei, Taiwan, 14-17 March 2016.

31. Jin, N.; Hu, S.; Gan, C.; Ling, Z. Finite States Model Predictive Control for Fault Tolerant Operation of Three-Phase Bidirectional AC/DC Converter Under Unbalanced Grid Voltages. IEEE Trans. Ind. Electron. 2018, 65, 819-829. [CrossRef]

32. Li, Y.; Fan, X. Recursive integral proportional-integral control based on membership cloud for active power filter. IET Power Electron. 2014, 7, 2870-2876. [CrossRef] 